\title{
RANCANG BANGUN MESIN STIRLING TIPE GAMA BERKAPASITAS 157 ML MENGGUNAKAN SISTEM PENDINGIN FLUIDA CAIR
}

\author{
Hari S. Ritonga ${ }^{1 *}$, Farel H. Napitupulu ${ }^{2}$, Tulus B. Sitorus ${ }^{3}$, M. Syahril Gultom ${ }^{4}$ \\ ${ }^{1,2,3,4}$ Departemen Teknik Mesin, Fakultas Teknik, Universitas Sumatera Utara \\ Email: ritonga732@gmail.com
}

\begin{abstract}
Research on the development of the stirling engine is currently being developed due to the characteristics of stirling engines that can use many types of fuel. The design of the cooling system on the Stirling engine is absolutely necessary to improve the efficiency and workability of the engine. The purpose of this study was to design a stirling engine using liquid coolers and to determine engine performance. The type of stirling machine used is a gama type stirling engine which has a higher efficiency than other types of stirling engines. Stirling engine designed with a capacity of $150 \mathrm{ml}$. The results obtained from the design of the stirling engine showed that the maximum engine performance on water use, the average combustion temperature of $694.05{ }^{\circ} \mathrm{C}$ and the average temperature of compression $48.29{ }^{\circ} \mathrm{C}$ obtained the engine speed of $540 \mathrm{rpm}$ and engine power of 24.2 watts. Engine performance without using water at an average temperature of combustion of $561.87^{\circ} \mathrm{C}$ and the average temperature of compression of $50.65{ }^{\circ} \mathrm{C}$ obtained engine speed of $444 \mathrm{rpm}$ and engine power of 16.42 watts. Thus it can be concluded that the use of liquid cooling on the Stirling engine will improve engine performance and power.
\end{abstract}

Keyword : stirling engine, liquid cooland, performance

\begin{abstract}
Abstrak
Penelitian tentang pengembangan mesin stirling saat ini sedang berkembang terkusus diakibatkan oleh karakteristik mesin stirling yang dapat mengunakan banyak jenis bahan bakar. Perancangan sistem pendingin pada mesin stirling sangat mutlak diperlukan untuk menigkatkan efisiensi dan ketahahan kerja mesin. Tujuan penelitian ini adalah merancang mesin stirling dengan menggunakan pendingin cairan serta untuk mengetahui performa mesin. Jenis mesin stirling yang digunakan adalah mesin stirling tipe gama yang mempunyai efisiensi lebih tinggi dari jenis mesin stirling lainnya. Mesin stirling yang dirancang berkapasitas $150 \mathrm{ml}$. Hasil penelitian yang diperoleh dari perancangan mesin stirling menunjukkan bahwa performa mesin maksimum pada penggunaan air, suhu rata-rata pembakaran $694,05{ }^{\circ} \mathrm{C}$ dan suhu ratarata kompresi $48,29{ }^{\circ} \mathrm{C}$ didapat putaran mesin $540 \mathrm{rpm}$ dan daya mesin 24,2 watt. Performa mesin tanpa menggunakan air pada suhu rata-rata pembakaran $561,87^{\circ} \mathrm{C}$ dan suhu rata-rata kompresi $50,65^{\circ} \mathrm{C}$ didapat putaran mesin $444 \mathrm{rpm}$ dan daya mesin 16,42 watt. Dengan demikian dapat disimpulkan penggunaan pendingin cairan pada mesin stirling akan meningkatkan performa dan daya mesin.
\end{abstract}

Kata kunci : mesin stirling, pendingin cairan, performa

\section{Pendahuluan}

Energi merupakan kebutuhan terbesar umat manusia, semakin bertambahnya populasi umat manusia maka konsumsi akan energi akan semakin bertambah. Salah satu sumber energi terbesar yang digunakan manusia adalah energi dari fosil. Hampir semua kegiatan produksi dan 
transfortasi menggunakan energi fosil sebagai bahan bakar. Penggunaan energi fosil yang secara terus menerus mengakibatkan persediaannya semakin lama semakin habis. Disamping persediaannya yang terbatas, penggunaan energi fosil sebagai sumber bahan bakar menyumbang polusi yang besar terhadap lingkungan. Cara yang di dapat gunakan untuk mengurangi penggunaan energi fosil adalah dengan mengembangkan teknologi dengan efisiensi penggunaan bahan bakar yang lebih maksimal serta pengembangan teknologi yang memanfaatkan energi terbarukan sebagai sumber energi utama.

Mesin stirling adalah mesin dengan sistem pembakaran luar siklus tertutup yang dapat menggunakan berbagai jenis bahan bakar seperti energi fosil, biomassa, energi surya, maupun energi nuklir sebagai bahan bakarnya namun mesin ini mempunyai kekurangan yaitu ketika mesin sudah mencapai panas berlebih maka akan mengakibatkan kinerja mesin berkurang dan bahkan mengakibatkan mesin berhenti berjalan.

Tujuan dari penelitian mesin stirling ini adalah merancang mesin stirling tipe gamma berkapasitas $157 \mathrm{ml}$ yang menggunakan pendingin cairan serta untuk mengetahui daya yang dibangkitkan mesin dan performa mesin ketika menggunakan pendingin cairan dan tanpa menggunakan pendingin cairan.

\section{Dasar Teori}

\section{Teori Schmidt}

Teori Schmidt adalah salah satu metode perhitungan isotermal untuk mesin Stirling. Ini adalah metode yang paling sederhana dan sangat berguna selama pengembangan mesin Stirling. Teori ini didasarkan pada ekspansi isotermal dan kompresi gas ideal. Performa mesin dapat dihitung menggunakan diagram P-V. Volume dalam mesin dapat dihitung dengan menggunakan geometri internal. Ketika volume, massa fluida bekerja dan suhu ditentukan, tekanan dapat dihitung dengan menggunakan metode persamaan gas ideal seperti yang ditunjukkan dibawah ini.

$\mathrm{PV}=\mathrm{mRT}$

Dimana :

$\mathrm{P}=$ tekanan $(\mathrm{Pa})$

$\mathrm{v}=$ volume $\left(\mathrm{M}^{3}\right)$

$\mathrm{m}=$ jumlah mol zat $(\mathrm{Kg})$

$\mathrm{r}=$ konstanta gas $(\mathrm{J} / \mathrm{Kg} \cdot \mathrm{K})$

$\mathrm{t}=\operatorname{suhu}(\mathrm{K})$

Berikut beberapa asumsi yang digunakan untuk menentukan Perhitungan mesin Stirling.

a) Tidak ada pressure loss dan tidak ada perbedaan internal pressure.

b) Proses ekspansi dan proses kompresi berlangsung secara isothermal.

c) Kondisi fluida kerja adalah udara sebagai gas ideal.

d) Terjadi regenerasi sempurna.

e) Volume sisa pada silinder panas menjaga temperatur gas pada silinder panas $-T_{E}$, volume sisa pada silinder dingin menjaga temperatur gas pada silinder dingin $-\mathrm{T}_{\mathrm{C}}$ selama siklus.

f) Temperatur pada regenerator adalah rata-rata ekspansi $-T_{E}$, dan temperatur kompresi - Tc .

g) Volume ekspansi (Ve) dan volume kompresi $(\mathrm{Vc})$ berubah berdasarkan fungsi sinusida. 


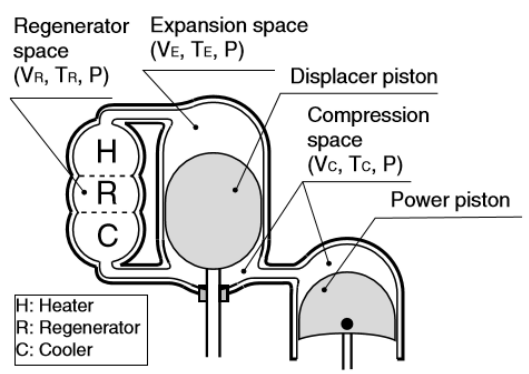

Gambar 2.1 mesin stirling tipe gama

Volume ekspansi momental $-\mathrm{V}_{\mathrm{E}}$, dan volume compresi momental $-\mathrm{V}_{\mathrm{C}}$ dideskripsikan pada persamaan dibawah ini dengan sudut putar $-\mathrm{x}$. Sudut putar didefinisikan sebagai $\mathrm{x}=0$ ketika piston ekspansi (piston pada silinder panas) berada pada posisi TMA. Sudut phasa $-\mathrm{dx}$ yaitu sudut antara piston displacer dan piston compresi.

$$
V e=\frac{V s e}{2}(1-\cos x)+V d e
$$

Volume kompresi sesaat $-\mathrm{Vc}$ dapat dihitung dengan persamaan (1) dan sudut fase $-\mathrm{dx}$

$$
\begin{array}{r}
\mathrm{Vc}=\frac{V_{S E}}{2}(1-\cos \mathrm{x})+ \\
\frac{V_{S C}}{2}\{1-\cos (\mathrm{x}-\mathrm{dx})\}+\mathrm{V}_{\mathrm{DC}}
\end{array}
$$

Volume total sesaat dihitung dengan persamaan :

$$
\mathrm{V}=\mathrm{Vc}+\mathrm{V}_{\mathrm{R}}+\mathrm{V}_{\mathrm{E}}
$$

Dengan asumsi (a), (b), dan (c), maka massa total dalam mesin, dapat dihitung dari tekanan, temperatur, volume dan tetapan gas konstan - $\mathrm{R}$

$$
\mathrm{m}=\frac{P V_{E}}{R T_{E}}+\frac{P V_{R}}{R T_{R}}+\frac{P V_{C}}{R T_{C}}
$$

Rasio tempratur $-\mathrm{t}$, rasio volume bersih $-\mathrm{v}$, dan rasio volume langkah dapat dihitung pada persamaan dibawah ini

$$
\begin{gathered}
t=\frac{T_{C}}{T_{E}} \\
v=\frac{V_{S C}}{V_{S E}} \\
X_{D E}=\frac{V_{D E}}{V_{S E}} \\
X_{D C}=\frac{V_{D C}}{V_{S E}} \\
X_{R}=\frac{V_{R}}{V_{S E}}
\end{gathered}
$$

Suhu regenerator $-T_{R}$, di rumuskan pada persamaan .... dengan asumsi (f), sebagai berikut :

$$
\mathrm{T}_{\mathrm{R}}=\frac{T_{E+T_{C}}}{2}
$$

Ketika persamaan (6) dan (10) di subsitusikan ke persamaan (5), maka untuk massa gas total diperoleh pada persamaan seperti dibawah ini

$$
\mathrm{m}=\frac{P}{R T_{C}}\left(\mathrm{tV}_{\mathrm{E}}+\frac{2 V_{R}}{1+t}+\mathrm{V}_{\mathrm{C}}\right)
$$

Dengan mensubsitusikan persamaan (2) dan (3) ke persamaan (12) maka diperoleh persaan

$$
\mathrm{m}=\frac{P V_{S E}}{2 R T_{C}}\{\mathrm{~S}-\mathrm{B} \cos (\mathrm{x}-\mathrm{a})\}
$$

Dimana : 


$$
\begin{gathered}
a=\tan ^{-1} \frac{v \sin d x}{t+\cos d x+1} \\
S=t+2 t X_{D E}+\frac{4 t V_{R}}{1+t}+v+2 X_{D C}+1 \\
B=\sqrt{t^{2}+2(t-1) v \cos d x+v^{2}-2 t+1}
\end{gathered}
$$

Tekanan mesin $-\mathrm{p}$, di tentukan dengan menggunakan persaan (13) sebagai berikut.

$$
\mathrm{P}=\frac{2 m R T_{C}}{V_{S E}\{S-B \cos (\theta-a)\}}
$$

Tekanan rata-rata di rumuskan dengan :

$$
\mathrm{P}_{\text {mean }}=\frac{1}{2 \pi} \oint P d x=\frac{2 m R T_{C}}{V_{S E} \sqrt{S^{2}-B^{2}}}
$$

c dirumuskan dengan persamaan :

$$
\mathrm{c}=\frac{B}{S}
$$

Perhitungan tekanan mesin berdasarkan tekanan rata-rata di rumuskan dengan persamaan :

$$
\mathrm{P}=\frac{P_{\text {mean }} \sqrt{S^{2}-B^{2}}}{S-B \cos (\theta-a)}=\frac{P_{\text {mean }} \sqrt{1-c^{2}}}{1-c \cdot \cos (x-a)}
$$

maka didapat persamaan untuk tekanan mesin sebagai berikut :

$$
\mathrm{P}=\frac{P_{\text {mean }} \sqrt{1+c^{2}}}{1-c \cdot \cos (x-a)}=\frac{P_{\min }(1+c)}{1-c \cdot \cos (x-a)}=\frac{P_{\max }(1-c)}{1-c \cdot \cos (x-a)}
$$

\section{Indikator Energi, Daya, dan Efisiensi}

Indikator energi pada ruang ekspansi dan kompresi di hitung berdasarkan solusi analitis degan menggunakan koefisien diatas.

Indikator energi pada daerah ekspansi $\left(\mathrm{W}_{\mathrm{E}}\right)$ dapat dihitung berdasarkan pada tekanan rata-rata, tekanan maximum, dan tekanan minimum. Seperti pada persamaan dibawah ini.

$$
\begin{array}{r}
\mathrm{W}_{\mathrm{E}}=\oint P d V_{E}=\frac{P_{\text {mean }} V_{S E} \pi c \sin a}{1+\sqrt{1-c^{2}}} \\
=\frac{P_{\min } V_{S E} \pi c \sin a}{1+\sqrt{1-c^{2}}} \frac{\sqrt{1+c}}{\sqrt{1-c}} \\
=\frac{P_{\min } V_{S E} \pi c \sin a}{1+\sqrt{1-c^{2}}} \frac{\sqrt{1-c}}{\sqrt{1+c}}
\end{array}
$$

Indikator energi pada area kompresi $\left(\mathrm{W}_{\mathrm{C}}\right)$, dirumuskan dengan persamaan dibawah ini.

$$
\begin{gathered}
\mathrm{W}_{\mathrm{C}}=\oint P d V_{C} \\
=-\frac{P_{\text {mean }} V_{S E} \pi c t \sin a}{1+\sqrt{1-c^{2}}} \\
=-\frac{P_{\min } V_{S E} \pi c t \sin a}{1+\sqrt{1-c^{2}}} \cdot \frac{\sqrt{1+c}}{\sqrt{1-c}} \\
=\frac{P_{\max } V_{S E} \pi c t \sin a}{1+\sqrt{1-c^{2}}} \cdot \frac{\sqrt{1-c}}{\sqrt{1+c}}
\end{gathered}
$$

Indikator energi per satu siklus mesin di hitung dengan menggunakan rumus dibawah ini.

$$
\begin{aligned}
\mathrm{W}_{\mathrm{i}} & =\mathrm{W}_{\mathrm{E}}+\mathrm{W}_{\mathrm{C}} \\
& =\frac{P_{\text {mean }} V_{S E} \pi c(1-t) \sin a}{1+\sqrt{1-c^{2}}} \\
& =\frac{P_{\min } V_{S E} \pi c(1-t) \sin a}{1+\sqrt{1-c^{2}}} \frac{\sqrt{1+c}}{\sqrt{1-c}} \\
& =\frac{P_{\max } V_{S E} \pi c(1-t) \sin a}{1+\sqrt{1-c^{2}}} \frac{\sqrt{1-c}}{\sqrt{1+c}}
\end{aligned}
$$

Hubungan antara $\mathrm{P}_{\text {mean, }}, \mathrm{P}_{\min }$, dan $\mathrm{P}_{\max }$ dirumuskan seperti dibawah ini.

$\frac{P_{\min }}{P_{\text {mean }}}=\sqrt{\frac{1-c}{1+c}}$ 
$\frac{P_{\min }}{P_{\text {mean }}}=\sqrt{\frac{1+c}{1-c}}$

Indikator daya pada saat ekspansi, compresi dan indikator daya untuk total keseluruhan sistem dirumuskan dengan persamaan berikut:

$\mathrm{L}_{\mathrm{E}}=\mathrm{W}_{\mathrm{E}} \mathrm{n}$

$\mathrm{L}_{\mathrm{C}}=\mathrm{W}_{\mathrm{C}} \mathrm{n}$

$\mathrm{L}_{\mathrm{I}}=\mathrm{W}_{\mathrm{In}}$

Diman :

$$
\begin{aligned}
& \mathrm{n}=\text { putaran mesin (rpm) } \\
& \mathrm{L}=\text { daya mesin (watt) } \\
& \mathrm{W}=\text { energi (joule) }
\end{aligned}
$$

Perhitungan efisiensi dari mesin stirling dapat dirumuskan dengan membandingkan energi yang di keluarkan oleh mesin $\left(\mathrm{W}_{\mathrm{I}}\right)$ dengan energi yang masuk $\left(\mathrm{W}_{\mathrm{E}}\right)$.

$$
\mathrm{e}=\frac{W_{i}}{W_{E}}=1-\mathrm{t}
$$

Dimana :

$$
\mathrm{e}=\text { efisiensi }(\%)
$$

\section{Unjuk Kerja Mesin}

daya yang bekerja pada poros dapat ditentukan dari persamaan di bawah ini.

$$
\mathrm{T}=\mathrm{Fr} \longrightarrow \mathrm{F}=\frac{T}{r}
$$

Dimana :

$$
\begin{aligned}
& \mathrm{T}=\operatorname{torsi}(\mathrm{Nm}) \\
& \mathrm{F}=\text { gaya }(\mathrm{N}) \\
& \mathrm{r}=\text { jari-jari }(\mathrm{m})
\end{aligned}
$$

Jarak yang ditempuh $\mathrm{s}$ adalah jumlah putaran dari poros dikali denga keliling poros. Dirumuskan dibawah ini

$\mathrm{s}=(2 \pi r) n$

Dimana :

$$
\begin{aligned}
& \mathrm{s}=\text { jarak yang ditempuh }(\mathrm{m}) \\
& \mathrm{r}=\text { jari-jari }(\mathrm{m}) \\
& \mathrm{n}=\operatorname{putaran}(\mathrm{rpm})
\end{aligned}
$$

kerja yang dilakukan oleh poros persatuan waktu dirumuskan [23]. Sebagai berikut.

$\mathrm{W}_{\mathrm{sh}}=\mathrm{Fs}=\left(\frac{T}{r}\right)(2 \pi \mathrm{r} . \mathrm{n})$

$\mathrm{W}_{\mathrm{sh}}=2 \pi \mathrm{nT}$

Dimana :

$$
\begin{aligned}
\mathrm{W}_{\mathrm{sh}} & =\text { daya poros }(\mathrm{watt}) \\
\mathrm{n} & =\text { putaran }(\mathrm{rpm})
\end{aligned}
$$

\section{Desain dan Pembuatan Alat}


Proses rancang bangun mesin stirling ini melalui beberapa tahap yaitu proses perhitungan awal untuk menetukan dimensi dari mesin yang dirancang, proses menggambar, dan selanjutna adalah proses produksi bagian-bagian mesin. Berikut adalah gambar rancagan mesin yang telah di buat

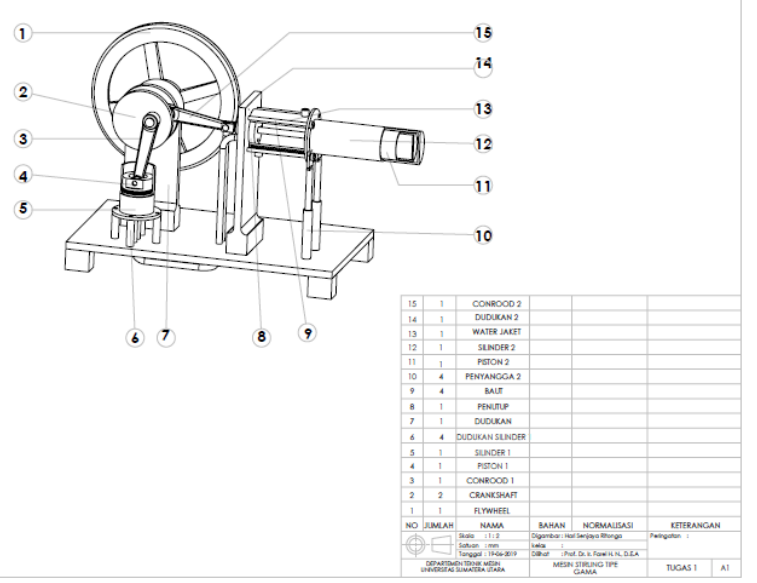

Gambar 3.1 Asembli Mesin Stirling

Gambar dia atas memperlihatkan bagian desain dari mesin stirling.

Berikut parameter dimensi untuk desainmesin stirliling yang dirancang.

Tabel 4.1 Parameter mesin stirling

\begin{tabular}{|c|c|c|c|}
\hline No & Nama & Simbol & Satuan \\
\hline 1 & $\begin{array}{l}\text { Volume } \\
\text { displacer }\end{array}$ & $\mathrm{V}_{\mathrm{SE}}$ & $157 \mathrm{~cm}^{3}$ \\
\hline 2 & $\begin{array}{c}\text { Volume mati } \\
\text { displacer }\end{array}$ & $\mathrm{V}_{\mathrm{DE}}$ & $9.81 \mathrm{~cm}^{3}$ \\
\hline 3 & Diameter silinder & $\mathrm{D}_{\mathrm{E}}$ & $50 \mathrm{~mm}$ \\
\hline 4 & Panjang langkah & $\mathrm{L}_{\mathrm{E}}$ & $80 \mathrm{~mm}$ \\
\hline 5 & $\begin{array}{l}\text { Pajang langkah } \\
\text { volume mati } \\
\text { dispalcer }\end{array}$ & $\mathrm{L}_{\mathrm{DE}}$ & $15 \mathrm{~mm}$ \\
\hline 6 & $\begin{array}{l}\text { Volume power } \\
\text { piston }\end{array}$ & $\mathrm{V}_{\mathrm{SC}}$ & $78.5 \mathrm{~cm}^{3}$ \\
\hline 7 & $\begin{array}{l}\text { Volume mati } \\
\text { power piston }\end{array}$ & $\mathrm{V}_{\mathrm{DC}}$ & $3.92 \mathrm{~m}^{3}$ \\
\hline 8 & Diameter silinder & $\mathrm{D}_{\mathrm{C}}$ & $50 \mathrm{~mm}$ \\
\hline 9 & Panjang langkah & $\mathrm{L}_{\mathrm{C}}$ & $40 \mathrm{~mm}$ \\
\hline 10 & $\begin{array}{l}\text { Pajang langkah } \\
\text { volume mati } \\
\text { power piston }\end{array}$ & $\mathrm{L}_{\mathrm{DC}}$ & $2 \mathrm{~mm}$ \\
\hline 11 & Sudut phasa & $\mathrm{dx}$ & $90^{\circ}$ \\
\hline 12 & $\begin{array}{l}\text { Tetapan gas } \\
\text { konstan }\end{array}$ & $\mathrm{R}$ & $\begin{array}{l}286,9 \\
\text { j/kg.k }\end{array}$ \\
\hline 13 & $\begin{array}{c}\text { Tekanan rata- } \\
\text { rata }\end{array}$ & $\mathrm{P}_{\text {mean }}$ & $101,3 \mathrm{kpa}$ \\
\hline
\end{tabular}




\begin{tabular}{|l|l|l|l|}
\hline 14 & $\begin{array}{l}\text { Dimaeter } \\
\text { Flywheel }\end{array}$ & $\mathrm{r}$ & $25 \mathrm{~mm}$ \\
\hline
\end{tabular}

\section{Data Hasil Penelitian}

Data penelitian pada mesin stirling terbagi menjadi tiga bagian yaitu data hasil pengujian degan menggunakan pendingin cairan, data pengujian tanpa menggunakan pendingin, dan data pengujian dengan menggunakan pembebanan pada mesin stirling.

a. data hasil pengujia menggunakan pendingin air

Tabel 4.1 Data pengujian menggunkan pendingin

\begin{tabular}{|l|c|c|c|c|c|}
\hline \multicolumn{1}{|c|}{ Keterangan } & $\begin{array}{c}\text { Interval Waktu } \\
\text { (menit) }\end{array}$ & $\begin{array}{c}\text { Putaran } \\
(\mathbf{r p m})\end{array}$ & $\begin{array}{c}\text { Suhu } \\
\text { Ekspansi } \\
\left({ }^{\mathbf{0}} \mathbf{C}\right)\end{array}$ & $\begin{array}{c}\text { Suhu } \\
\text { kompresi } \\
\left({ }^{\mathbf{0}} \mathbf{C}\right)\end{array}$ & $\begin{array}{c}\text { Suhu air } \\
\text { masuk } \\
\left({ }^{\mathbf{0}} \mathbf{C}\right)\end{array}$ \\
\hline Mesin dijalankan & 3.43 & 185 & 386,75 & 34,31 & 26 \\
\hline $\begin{array}{l}\text { Performa mesin } \\
\text { rata-rata }\end{array}$ & $12.00-29.20$ & 540 & 694,05 & 48,29 & 26 \\
\hline $\begin{array}{l}\text { Performa mesin } \\
\text { maksimum }\end{array}$ & 22.00 & 578 & 718,73 & 50,49 & 26 \\
\hline
\end{tabular}

Berikut dibawah ini adalah diagram P-V mesin stirling dengan mengunakan pendingin cairan.

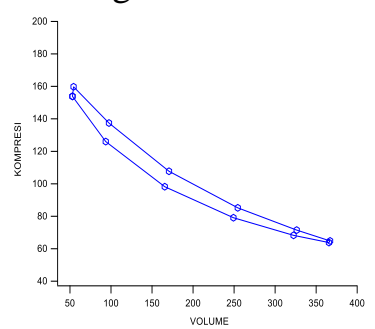

Gambar 4. 2 diagram P-V dengan menggunkan pendingin

b. pengujian tanpa menggunkan pendingin 
Tabel 4.2 data pengujian tanpa menggunakan pendingin

\begin{tabular}{|c|c|c|c|c|c|}
\hline Keterangan & $\begin{array}{c}\text { Interval Waktu } \\
(\mathbf{m} \text { (mit) }\end{array}$ & $\begin{array}{c}\text { Putaran } \\
(\mathbf{r p m})\end{array}$ & $\begin{array}{c}\text { Suhu } \\
\text { Ekspansi } \\
\left({ }^{\mathbf{0}} \mathbf{C}\right)\end{array}$ & $\begin{array}{c}\text { Suhu } \\
\text { kompresi } \\
\left({ }^{\mathbf{0}} \mathbf{C}\right)\end{array}$ & $\begin{array}{c}\text { Suhu } \\
\text { ruangan } \\
\left({ }^{\mathbf{0}} \mathbf{C}\right)\end{array}$ \\
\hline Mesin dijalankan & 12.20 & 326 & 269,9733 & 34,5295 & 32 \\
\hline $\begin{array}{c}\text { Performa mesin } \\
\text { rata-rata }\end{array}$ & $21.00-40.00$ & 444 & 561,87 & 50,65 & 32 \\
\hline $\begin{array}{c}\text { Performa mesin } \\
\text { maksimum }\end{array}$ & 18.00 & 569 & 638,5959 & 40,6427 & 32 \\
\hline
\end{tabular}

Berikut dibawah ini adalah diagram P-V mesin stirling tanpa mengunakan pendingin cairan.

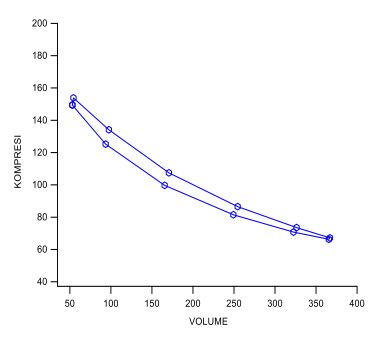

Gambar 4.3 diagram P-V tanpa menggunakan pendingin

c. data pengujian dengan menggunakan pembebanan.

Tabel 4.6 data hasil pengujian putaran mesin berdasarkan pembebanan

\begin{tabular}{|c|c|c|c|c|c|c|}
\hline No & $\begin{array}{c}\text { Massa } \\
(\mathbf{k g})\end{array}$ & $\begin{array}{c}\text { Torsi } \\
(\mathbf{N m})\end{array}$ & $\begin{array}{c}\text { Daya } \\
(\mathbf{W a t t})\end{array}$ & $\begin{array}{c}\text { Putaran } \\
(\mathbf{R P M})\end{array}$ & $\begin{array}{c}\text { Suhu } \\
\text { Kompresi }\left({ }^{(} \mathbf{C}\right)\end{array}$ & $\begin{array}{c}\text { Suhu } \\
\text { Ekspansi }\left({ }^{\mathbf{}} \mathbf{C}\right)\end{array}$ \\
\hline 1 & 1 & 0,245 & 11,38 & 444 & 36,07 & 638,29 \\
\hline 2 & 1,3 & 0,319 & 14,49 & 434 & 37,49 & 636,89 \\
\hline 3 & 1,6 & 0,392 & 16,15 & 393 & 38,14 & 627,60 \\
\hline 4 & 1,9 & 0,466 & 17,23 & 353 & 37,73 & 620,65 \\
\hline 5 & 2,2 & 0,540 & 18,08 & 320 & 37,05 & 620,08 \\
\hline 6 & 3,1 & 0,761 & 23,33 & 293 & 37,36 & 595,67 \\
\hline 7 & 3,7 & 0,90 & - & - & 37,66 & 608,61 \\
\hline
\end{tabular}

\section{Kesimpulan}

Berikut kesimpulan yang didapat dari rancang bangun mesin stirling tipe gamma berkapasits $157 \mathrm{ml}$ dengan menggunakan pendingin air. 
1. Performa mesin yang diperoleh yaitu sebesar 23,33 watt pada putaran $293 \mathrm{rpm}$ dengan melakukan pembebanan, putaran mesin maksimum sebesar $576 \mathrm{rpm}$ tanpa pembebanan, torsi maksmum mesin adalah sebesar $0,9 \mathrm{Nm}$.

2. Performa mesin terbaik didapat ketikan mesin menggunakan pendingin air, yaitu putara mesin rata-rata adalah $540 \mathrm{rpm}$ dengan suhu rata-rata ekspansi $694,05{ }^{\circ} \mathrm{C}$ dan suhu rata-rata kompresi $48,29{ }^{\circ} \mathrm{C}$, sedangkan tanpa menggunakan pendingin diperoleh putaran mesin ratarata $444 \mathrm{rpm}$ dengan suhu rata-rata ekspansi $561,87^{\circ} \mathrm{C}$ dan suhu rata-rata kompresi $50,65^{\circ} \mathrm{C}$. Berdasarkan analisis schmidt daya yang dibangkitkan pada penggunaan pendingin air adala $\mathrm{h}$ sebesar 24,2 watt sedangkan tanpa menggunakan pendingin daya yang dibangkitkan mesin sebesar 16,42 watt

3. Berdasarkan pengukuran torsi yaitu sebesar $0,761 \mathrm{Nm}$ pada putaran $293 \mathrm{rpm}$ diperoleh daya mesin sebesar 23,33 watt dengan suhu displacer $595,61^{\circ} \mathrm{C}$ dan suhu kompresi $37,36^{\circ} \mathrm{C}$

\section{Daftar Pustaka}

[1] G. Walker. (1980). Stirling Engine. Calendron press. Universitas Oxford.

[2] Andreas Wagner. 2008. Calculations and experiments on y-type Stirling engines. Tesis. Universitas Walles.

[3] Cengel, Y. A., dan Boles, M. A. 2015. Thermodynamic An Engineering Approch, eight edition. New York: McGraw-Hill Education,

[4] L. W. Rosenegger. 1973. Design And Development Of A Rotary Stirling Cycle Engine. Tesis. Universitas McGill Montreal.

[5] Hirata Koichi. Bekkome Home Page. Schmidt Theory for Stirling Engines. Stirling engine home page [online]. Diakses pada tanggal 17 januari 2019. Dari :http://www.bekkoame.ne.jp/ khirata/academic/indexe.htm

[6] Moran, Michael J., Shapiro, Howard N., dkk. 2014. Fundamental of Engineering Thermodynamics. eight editon. Hoboken: John Wiley \& Sons, Inc. All rights reserved 